\title{
A Comparative Study of Natural Convective Transfer in Rectangular and Square Geometry Micro Fins
}

\author{
D. Deepa*, R. Thanigaivelan, K. Gunasekaran, S. Praveenkumar \\ Mechanical Engineering, Muthayammal Engineering College (Autonomous), Rasipuram 637408, India
}

Corresponding Author Email: tvelan10@gmail.com

https://doi.org/10.18280/ti-ijes.652-444

Received: 21 March 2021

Accepted: 26 May 2021

\section{Keywords:}

free convection, buoyancy force, EDM, square, rectangular

\begin{abstract}
The increase in usage of high performance micro-electronic components leads to increase in high heat generation. In order to increase the life time of the electron devices proper ventilation of heat needs to be planned with the available space. In the electronic system the space occupied by the heat sink is small, as well as the heat has to be dissipated without disturbance. There are two types of cooling arrangement namely active cooling and passive cooling. Active cooling requires additional system such as blower and fan over passive cooling. In this study rectangular and square fin micro-fins are fabricated on copper and aluminium for a height of $0.25 \mathrm{~mm}$, with spacing and thickness of $5 \mathrm{~mm}$ to study the natural convective heat transfer. The study reveals that the rectangular geometry enhances the heat transfer rate by $3 \%$ compared to the square fin.
\end{abstract}

\section{INTRODUCTION}

Recent development in electronic industries attributes for high performance microelectronic components. These components generate heat energy which is to be properly vented out without damaging the performance of the microelectronic components. Hence researches on micro-fin for natural convective heat transfer were systematically studied. Turkyilmazogu [1] has analyzed the natural heat transfer through longitudinal fins using parameters such as fin temperature, fin efficiency and fin base temperature. In this experimentation, rectangular fins, longitudinal fins and hyperbolic shapes are compared. The result shows $12 \%$ increase in heat transfer for rectangular profile when compared with longitudinal and hyperbolic shapes. Khonsue [2] have conducted a study using rectangular fins, cylindrical pin fins, spiral pin fins with the size of $36 \times 28 \times 9 \mathrm{~mm}$ and fin height of $5 \mathrm{~mm}$. Among these fins, spiral pin fin are more suitable for electronic heat sink applications. Prasher et al. [3] have fabricated paper silicon staggered micro- fin in both circular and rectangular shapes and tested under natural convection condition. The result shows that a circular fin $<100 \mu \mathrm{m}$ is suitable for electronic cooling applications. Wan and Joshi [4] have studied the effect of micro fluidic cooling in cooling high power micro systems. The effect of pin fin dimension including diameter, transversal and longitudinal spacing and height are investigated experimentally. The performances of circular and square pin fin arrays are compared and the result shows that the circular array shows better thermal performance. Zhao et al. [5] have enhanced the heat transfer rate in micro square pin -fin heat sink. The parameters like pin fin, porosity and pin-fin angle are numerically and experimentally analyzed. The result is better at 0.75 porosity and $30^{\circ}$ angle and square pin fin gives better result which can be widely used in high power density chip. Sadaoui et al. [6] have experimentally analyzed the heat transfer and fluid flow in a square enclosure with finned plate at the outlet. They concluded that flow structure and wall heat transfer inside the enclosure depends on dimensionless parameter at the outlet. Micheli et al. [7] experimentally investigated the heat transfer performance of squared silicon wafer micro-fin. The study reported that the radiative heat transfer can contribute up to the $60 \%$ of the net thermal exchange. Costa et al. [8] have used plate heat exchanger along the engine cooling circuit in Diesel engine. Tullius et al. [9] have used different geometries such as circle, square, triangle, ellipse, diamond and hexagonal and analyzed the convection heat transfer dissipation. The reports that the triangular fins with larger fin height, smaller fin width, and spacing double the fin width increases the fin numbers in the area contributing for better performance. Hence in this research rectangular and square fin micro-fins are fabricated on copper and aluminium materials for a height of $0.25 \mathrm{~mm}$, spacing and thickness of $5 \mathrm{~mm}$ respectively to study the natural convective heat transfer. The study reveals that the rectangular geometry enhances the heat transfer rate by $3 \%$ compared to the square fin.

\section{EXPERIMENTAL SETUP}

Micro-fins are fabricated through electrical discharge machining (EDM) process. The experimental set shown in Figure 1 is used for analyzing micro fin heat transfer through conduction, convection and radiation.

$$
\text { Qconduction }=\text { Qradiation }+ \text { Qconvection }
$$

The micro-fin array with dimension of height $0.25 \mathrm{~mm}$, spacing and thickness $5 \mathrm{~mm}$ is generated on the test specimen. Totally 4 test pieces with same dimensions are fabricated. The fabricated test piece was heated with 12 Watts supply for 4 hours. The test pieces is covered with fibre glass box and further covered with styropor block. The specimen was heated by supplying $\mathrm{AC}$ voltage using step down transformer. The 
experiments are carried out with the help of auto transformer, ammeter, voltmeter and heating element. Heating element is kept at the bottom of the test pieces and constant 12 Watts power supply was given to the specimen and readings were taken for every one hour [10-12]. The specimen is totally covered with insulating material and heat will be added from the bottom side of the test piece. Only the top surface will have heat transfer to the atmosphere. Every one hour the top surface temperature and air temperature of the specimen were noted. Finally the convective heat transfer coefficient was calculated. Tables 1-4 shows the observed readings for the rectangular and square fins of aluminium and copper. The table provides the details of time of heating, top surface temperature of the micro-fin, air temperature and convective heat transfer coefficient. Convective heat transfer co efficient was calculated using the relation provided below [13-17]:

$$
N u=1.18\left[R a(r / H)^{\wedge} 4(r / L)^{\wedge} 4\right]^{\wedge} 0.147
$$

$\mathrm{Ra}$ is Rayleigh Number, $\mathrm{Nu}$ is Nusselt Number, $\mathrm{r}$ is radius of curvature

$$
\begin{gathered}
R a=g \beta(T w-T a) r^{\wedge 3} / \gamma \alpha \\
r=\frac{2 . H S}{2 \cdot H+S} \\
N u=h \mathrm{c} r / k a
\end{gathered}
$$

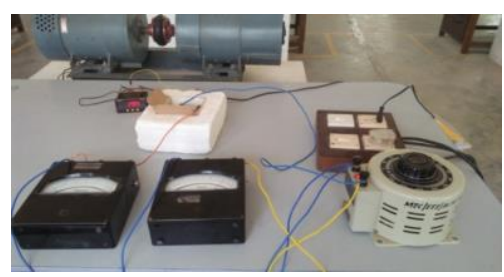

Figure 1. Experimental set up

Table 1. Coefficient of heat transfer for aluminium rectangular fin

\begin{tabular}{cccc}
\hline Time in hour & Top surface temperature $(\mathrm{Ts})$ in ${ }^{\circ} \mathrm{C}$ & Air temperature $(\mathrm{Ta})$ in ${ }^{\circ} \mathrm{C}$ & $\mathrm{h} \mathrm{W} / \mathrm{m} 2 \mathrm{~K}$ \\
\hline 1 & 77.8 & 45.7 & 3.667 \\
2 & 82.2 & 57.6 & 3.569 \\
3 & 102.2 & 67.7 & 3.764 \\
4 & 106.0 & 73.3 & 3.89 \\
\hline
\end{tabular}

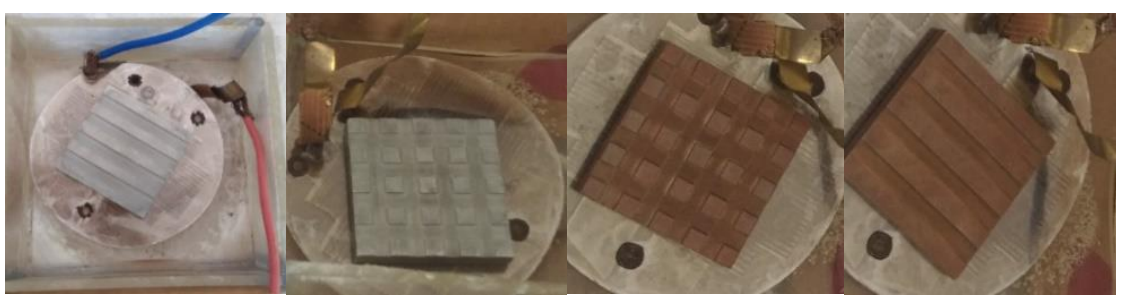

Figure 2. Different Geometries of micro-fin

Table 2. Coefficient of heat transfer for aluminium square fin

\begin{tabular}{cccc}
\hline Time in hour & Top surface temperature of micro-fin $(\mathrm{Ts}){ }^{\circ} \mathrm{C}$ & Air temperature $(\mathrm{Ta}){ }^{\circ} \mathrm{C}$ & $\mathrm{h} \mathrm{W} / \mathrm{m}^{2} \mathrm{~K}$ \\
\hline 1 & 72.1 & 55.8 & 3.36 \\
2 & 74 & 58.2 & 3.35 \\
3 & 79.7 & 63.4 & 3.43 \\
4 & 97.8 & 70.5 & 3.62 \\
\hline
\end{tabular}

Table 3. Coefficient of heat transfer for copper rectangular fin

\begin{tabular}{cccc}
\hline Time in hour & Top surface temperature of micro-fin $(\mathrm{Ts}){ }^{\circ} \mathrm{C}$ & Air temperature $(\mathrm{Ta}){ }^{\circ} \mathrm{C}$ & $\mathrm{h} \mathrm{W} / \mathrm{m}^{2} \mathrm{~K}$ \\
\hline 1 & 106.7 & 70.2 & 3.46 \\
2 & 112.8 & 76.4 & 3.86 \\
3 & 116 & 82 & 3.77 \\
4 & 128.8 & 85 & 4.40 \\
\hline
\end{tabular}

Table 4. Coefficient of heat transfer for copper square fin

\begin{tabular}{cccc}
\hline Time in hours & Top surface temperature of micro-fin $(\mathrm{Ts}){ }^{\circ} \mathrm{C}$ & Air temperature $(\mathrm{Ta}){ }^{\circ} \mathrm{C}$ & $\mathrm{h} \mathrm{W} / \mathrm{m}^{2} \mathrm{~K}$ \\
\hline 1 & 121 & 78 & 5.19 \\
2 & 112 & 73 & 5.05 \\
3 & 133 & 88 & 4.41 \\
4 & 126 & 86 & 4.03 \\
\hline
\end{tabular}

\section{RESULTS AND DISCUSSION}

The Figure 3 shows the relation between time and convective heat transfer coefficient. The heat transfer increases with time. The convective heat transfer coefficient for square fin is lower than rectangular fins. When the surfaces of the micro fin are heated the air density present in the surface becomes lesser. This less density air moves upward and high density air tries to replace the low density air. This mechanism of density difference creates the buoyancy force. A heat sink 
like square fins will have large surface area and closely packed fins will have greater surface area for heat transfer. The heat transfer coefficient of square is found to be lesser compared to rectangular fins due to the extra resistance created in square fins. In square fins the closely packed fins introduce fluid flow (air flow) through the inter fin passages thereby increasing the frictional force and reducing the buoyancy force. This decrease in buoyancy force reduces the heat transfer rate. So heat sinks with closely spaced fins are not suitable for natural convection cooling.

Figure 4 shows the convective heat transfer of copper square fins. The convective heat transfer is found to high in square micro fins due to the fact that increase in surface area leads to higher heat transfer rate. On increasing the heating time the temperature on the fin is distributed over the fin surfaces. Due to high thermal conductivity of copper enhanced heat transfer rate is achieved in the square micro-fin.

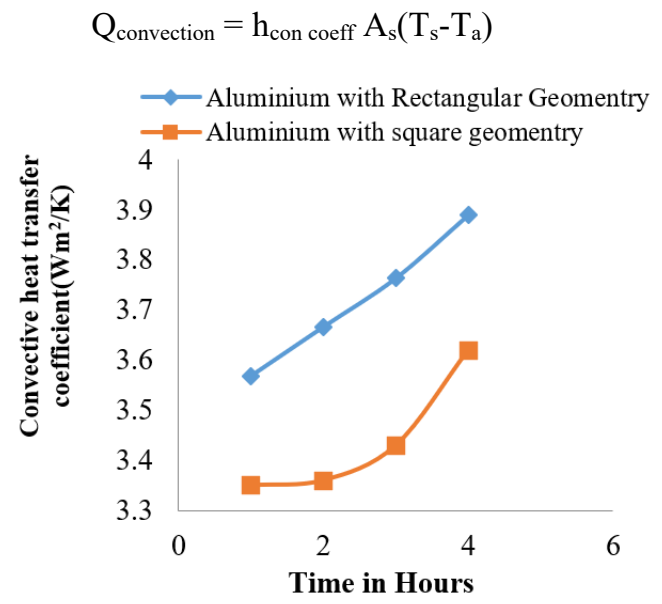

Figure 3. The relationship between $\mathrm{h}$ and time of heating for aluminium material

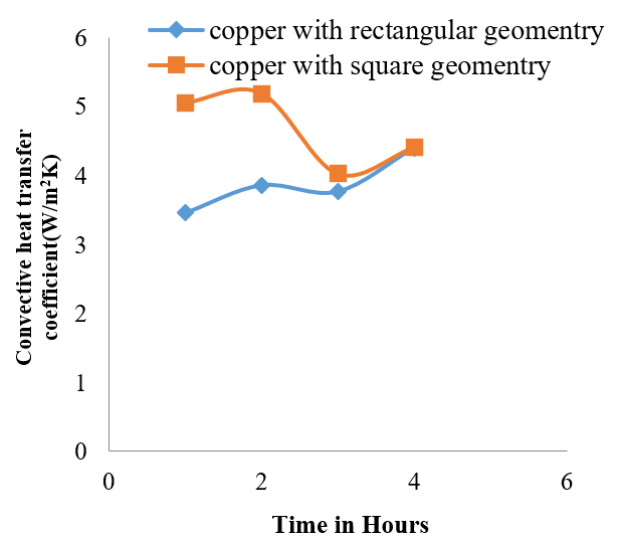

Figure 4. The convective heat transfer of copper square fins

\section{ANALYSIS OF MICRO -FINS}

The experimental results are compared with well established correlations using ANSYS CFX 15.0. CFD computational domain consists of four sub domains: heat sink (Aluminium / Copper specimen), insulation material, heating element and surrounding air [18]. An air gap of $1 \mathrm{~mm}$ between the heat sink and the surrounding insulation is modelled. To confine the computational domain, the air above the insulation and copper specimen is surrounded by an open vertical cylinder of $15 \mathrm{~cm}$ radius and $60 \mathrm{~cm}$ height. ICEM-CFD mesh generator is utilized for meshing the geometry. The mesh consists of 8,57,564 nodes of the hexahedral type with 36976 nodes in the copper specimen, 2,05,609 in the insulation, and 4,300 nodes in the heater sub domain. ANYS CFX, a commercial CFD package is employed to solve the steady state governing equations for conjugating heat transfer problem. The cylinder is modelled as a smooth adiabatic wall with an open boundary condition at its top to allow the air flow to go in and out of the computational domain. The bottom and side surfaces of the insulation material are modelled as adiabatic boundaries. The temperature of flow from the top is $293^{\circ} \mathrm{K}$ and the pressure 1.01325 bar. The heat is added to the domain through a source term in the energy equation of the heating element. The buoyant flow above the copper micro-fin and inside the cylinder is modelled as laminar natural convective heat transfer condition with the inclusion of radiation effects. The sample of copper and aluminium micro-fin with $5 \mathrm{~mm}$ spacing is taken and the CFD images provided for square and rectangular geometry. The above figure shows temperature distribution in copper and aluminium micro-fin for rectangular and square geometry. Figures 5-8 (a-c) shows the temperature, heat distribution and buoyancy effect and compared with the experimental results. The results are matches with the experimental results.

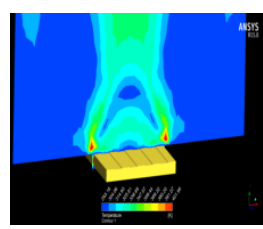

(a)

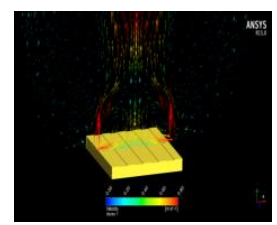

(b)

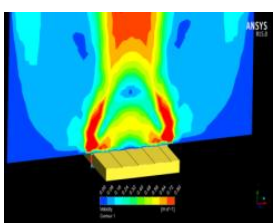

(c)
Figure 5. Temperature, heat distribution and buoyancy effect of copper specimen (Rectangular fin geometry)

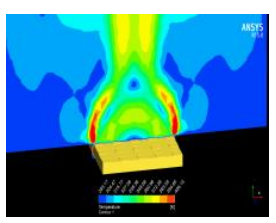

(a)

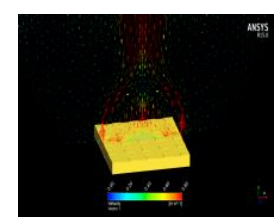

(b)

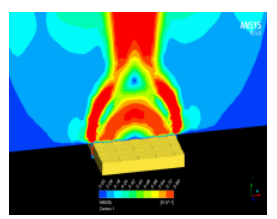

(c)
Figure 6. Temperature, heat distribution and buoyancy effect of copper specimen (Square fin geometry)

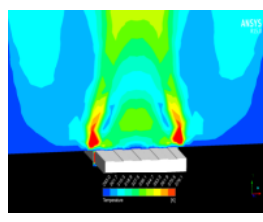

(a)

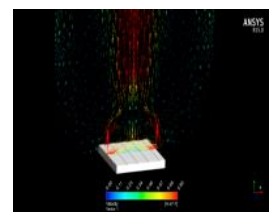

(b)

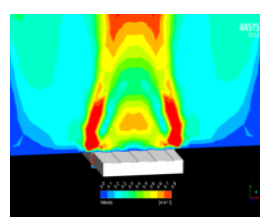

(c)
Figure 7. Temperature, heat distribution and buoyancy effect of aluminium specimen (Rectangular fin geometry)

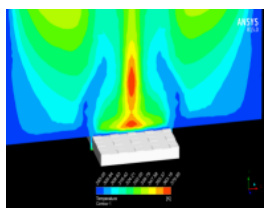

(a)

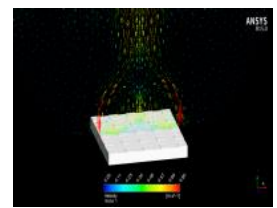

(b)

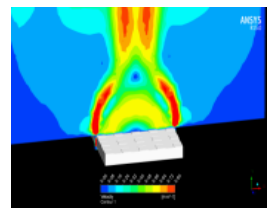

(c)
Figure 8. Temperature, heat distribution and buoyancy effect of aluminium specimen (Rectangular fin geometry) 


\section{CONCLUSIONS}

A rectangular and square fins micro fin was fabricated through electric discharge process by using copper and aluminium metal with specification of $0.25 \mathrm{~mm}$ height, $5 \mathrm{~mm}$ spacing, $5 \mathrm{~mm}$ thickness, $45 \mathrm{~mm}$ length and $45 \mathrm{~mm}$ breadth. The fabricated micro-fins are tested for convective heat transfer using the developed experimental setup. The convective heat transfer coefficient of copper and aluminium rectangular and square fins are and the rectangular fin shows highest heat transfer compared to aluminium square fin. The copper micro with square geometry shows the highest convective heat transfer coefficient compared to the tested specimen in this study. Hence copper with square geometry can be considered for heat sink applications

\section{REFERENCES}

[1] Turkyilmazoglu, M. (2014). Heat transfer through longitudinal fins. Journal of Thermophysics and Heat Transfer, 28(4):

806-811. https://doi.org/10.2514/1.T4348

[2] Khonsue, O. (2018). Enhancement of the forced convective heat transfer on mini pin fin heat sinks with micro spiral fins. Heat and Mass Transfer, 54(2): 563570. https://doi.org/10.1007/s00231-017-2159-4

[3] Prasher, R.S., Dirner, J., Chang, J.Y., Myers, A., Chau, D., He, D., Prstic, S. (2007). Nusselt number and friction factor of staggered arrays of low aspect ratio micropinfins under cross flow for water as fluid. Journal of Heat Transfer, 129(2): https://doi.org/10.1115/1.2402179

[4] Wan, Z., Joshi, Y. (2014). Pressure drop and heat transfer characteristics of square pin fin enhanced microgaps in single phase microfluidic cooling. Fourteenth Intersociety Conference on Thermal and Thermomechanical Phenomena in Electronic Systems (ITherm), Orlando, FL, USA, pp. 649-657. https://doi.org/10.1109/ITHERM.2014.6892343

[5] Zhao, J., Huang, S., Gong, L., Huang, Z. (2016). Numerical study and optimizing on micro square pin-fin heat sink for electronic cooling. Applied Thermal Engineering, 93: 1347-1359. https://doi.org/10.1016/j.applthermaleng.2015.08.105

[6] Sadaoui, D., Sahi, A., Nadjib, H., Meziani, B., Amoura, T. (2015). Free convection in a square enclosure with a finned plate. Mechanics \& Industry, 16(3): 310. https://doi.org/10.1051/meca/2015005

[7] Micheli, L., Reddy, K.S., Mallick, T.K. (2015). General correlations among geometry, orientation and thermal performance of natural convective micro-finned heat sinks. International Journal of Heat and Mass Transfer, 91:

711-724 https://doi.org/10.1016/j.ijheatmasstransfer.2015.08.015

[8] Costa, M., Cirillo, D., Rocco, V., Tuccillo, R., La Villetta, M., Caputo, C., Martoriello, G. (2019). Characterization and optimization of heat recovery in a combined heat and power generation unit. TECNICA ITALIANA-Italian Journal of Engineering Science, 63(2-4): 447-451. https://doi.org/10.18280/ti-ijes.632-448
[9] Tullius, J.F., Tullius, T.K., Bayazitoglu, Y. (2012). Optimization of short micro pin fins in minichannels. International Journal of Heat and Mass Transfer, 55(1516): 3921-3932. https://doi.org/10.1016/j.ijheatmasstransfer.2012.03.022

[10] Thanigaivelan, R., Deepa, D. (2018). Heat transfer enhancement by coated fins in the microscale domain. Thermal Science, 22(6 Part B): 2783-2789. https://doi.org/10.2298/TSCI160901089T

[11] Thanigaivelan, R., Deepa, D., Mythili, T., Arunachalam, R.M. (2017). Experimental Investigation of Natural Convective Heat Transfer Around Micro-fin Arrays. Journal of Scientific \& Industrial Research, 76: 501-505.

[12] Deepa, D., Thanigaivelan, R. (2018) Influence of nano silicon carbide and alumina reinforced aluminium fins for natural convective heat transfer. Proceedings of the Fifth International Conference on Therma Comp, pp. 241-244.

[13] Deepa, D., Thanigaivelan, R., Venkateshwaran, M. (2021). Identifying a suitable micro-fin material for natural convective heat transfer using multi-criteria decision analysis methods. Materials Today: Proceedings, 45: 1655-1659. https://doi.org/10.1016/j.matpr.2020.08.480

[14] Escher, W., Michel, B., Poulikakos, D. (2010). A novel high performance, ultra thin heat sink for electronics. International Journal of Heat and Fluid Flow, 31(4): 586598.

https://doi.org/10.1016/j.ijheatfluidflow.2010.03.001

[15] Kothandaraman, C.P. (2006). Fundamentals of heat and mass transfer. New Age International.

[16] Sachdeva, R.C. (2003). Fundamentals of Engineering Heat \& Mass Transfer-Second edition (New age International (P) Limited, New Delhi.

[17] Engel, Y.A. (2007). Heat \& Mass Transfer -A Practical Approach. Tata McGraw-Hill Education Pvt Ltd, New Delhi.

[18] Elguerri, M. (2020). 3D transient heat transfer simulation of spray cooling on titanium alloy slab. TECNICA ITALIANA-Italian Journal of Engineering Science, 64(2-4): 216-224. https://doi.org/10.18280/ti-ijes.642414

\section{NOMENCLATURE}

Q Heat transfer

h Heat transfer coefficient

$r \quad$ Radius of curvature, $m . s^{-2}$

Ra Rayleigh Number

$\mathrm{Nu} \quad$ Nusselt number along the heat source

L Characteristics Length

g Acceleration due to gravity

\section{Greek symbols}

$\alpha \quad$ thermal diffusivity, $\mathrm{m}^{2} . \mathrm{s}^{1}$

$\beta \quad$ thermal expansion coefficient, $\mathrm{K}^{-1}$

$\mu \quad$ dynamic viscosity, $\mathrm{kg} \cdot \mathrm{m}^{-1} \cdot \mathrm{s}^{-1}$ 